\title{
Historical Development, Applications and Advances in Materials Used in Spectacle Lenses and Contact Lenses
}

This article was published in the following Dove Press journal: Clinical Optometry

\author{
Rayishnee Pillay (iD \\ Rekha Hansraj (iD ${ }^{2}$ \\ Nishanee Rampersad (iD ${ }^{2}$ \\ 'University of KwaZulu-Natal, Durban, \\ South Africa; ${ }^{2}$ Discipline of Optometry, \\ University of KwaZulu-Natal, Durban, \\ South Africa
}

\begin{abstract}
Lenses used in vision correction have evolved from the initial glass reading stone of the 10th century to the currently anticipated planar metalens made from "nanopillars" of titanium dioxide. With ideas from early scientific minds being translated into reality, and military commissioned concepts adapted for civilian use, spectacle lens and contact lens materials have progressed significantly over the last century, with the expectation of further lens material innovations ahead. The purpose of this article is a review of literature on the historical developments and advances in spectacle lens and contact lens materials.
\end{abstract}

Keywords: spectacle lens materials, contact lens materials, historical perspective, advances in lens materials

\section{Introduction}

Visual impairment (VI) refers to a functional limitation of the eyes or visual system due to a disorder or disease resulting in the affected individual being unable to perform vision-related tasks associated with daily living. ${ }^{1}$ It is estimated that 1.3 billion people worldwide have some form of VI. ${ }^{2}$ Approximately $80 \%$ of VI is considered avoidable, with uncorrected refractive error being one of the leading causes. $^{2}$ Refractive errors are broadly classified into myopia, hyperopia, astigmatism and presbyopia, ${ }^{3}$ and may be corrected with the use of spectacles, contact lenses or surgery. This review article will describe the historical development, applications and advances in materials used in spectacle lenses and contact lenses.

\section{Materials and Methods}

Various online databases including Crossref, Google Scholar, PubMed, EBSCOhost, were searched for scientific papers using key words related to the topic. Reference lists from scientific papers, as well as spectacle lens and contact lens manufacturer/supplier websites, were also considered. Over 100 documents were initially sourced, of which 47 were selected to be used in this review.

\section{Spectacle Lenses}

\section{Historical Development}

The earliest documented reading device was glass "reading stones" used by monks in the 10th century AD, while limited records suggest that spectacles were possibly invented in Florence, Italy, between 1280 and 1300. ${ }^{4}$ These were handheld and 
comprised of two convex quartz lenses surrounded by a ring of oakwood or horn riveted together, which were likely used to correct presbyopia. ${ }^{4}$ Venice dominated the spectacle lens industry in the early 14th century, while the advent of the printing press in the middle of the 15th century resulted in an increased accessibility to printed material and intensifying the demand for spectacles. ${ }^{4}$

It was only in the latter half of the 16th century that spectacle lens processing was differentiated from glassmaking, and that lenses were graded by their focal power. ${ }^{4}$ Travelling peddlers would sell spectacles on a trial basis ${ }^{4}$ as there were no measurements of refractive error at that time.

To better understand the development and use of spectacle lenses, advances within the field of optometric examination and instrumentation should be considered. Hermann von Helmholtz unveiled the direct ophthalmoscope in $1850,{ }^{5}$ and the ophthalmometer in $1855 .{ }^{3}$ The Snellen acuity chart was introduced in $1862^{5}$ while the unit of refractive error measurement, the dioptre, was proposed by Felix Monoyer in $1872^{5}$ and experiments with the ophthalmoscope by Ferdinand Cuignet led to the first objective measurement of refractive errors in $1873 .{ }^{4}$ Based on these documented historical developments, it is interesting to note that the measurement of refractive errors developed well after the manufacture and use of spectacles.

Spectacle lenses were made exclusively of glass until the introduction of polymeric or plastic materials. ${ }^{3}$ After World War I, advances in polymer technology resulted in new forms of plastics, with the most significant to the optical industry being the invention of polymerized methyl methacrylate (PMMA) in the 1930s. ${ }^{6}$ Having good optical properties, it was used in the manufacture of spectacle lenses until the 1940s when an acrylic resin made of allyl diglycol carbonate $\left(\mathrm{CR}-39^{\circledR}\right)$ was invented. ${ }^{6}$

Even though glass was still widely used, the manufacture and processing of CR-39 ${ }^{\circledR}$ as optical lenses began on a mass scale in $1946 .{ }^{6}$ However, a safety requirement for glass lenses introduced by the United States (US) Food and Drug Administration (FDA) in 1972, along with the prevailing trend of larger frame eye sizes resulted in an increased thickness and weight of glass lenses, which enhanced the popularity of plastic lenses. ${ }^{3}$

\section{Glass Materials}

Glass materials had been used for several centuries in spectacle lens manufacture as its properties made it almost ideal for optical use. ${ }^{3}$ It is a highly transparent material that resists most chemicals, does not discolour on aging, and is relatively scratch resistant. ${ }^{3}$ Traditionally spectacle lenses were made of crown glass which is a relatively unstructured material consisting of ions arranged in a random manner, made of a mixture of sand, soda, and lime, ${ }^{3}$ with a refractive index of 1.523 and is low in chromatic aberrations. ${ }^{7}$

The addition of barium oxide to the glass mixture in 1880 created a material of higher refractive index. ${ }^{3}$ By 1973, alkaline metal oxides such as zinc oxide and titanium dioxide were used to create thinner lenses of high refractive index with good chemical resistance, that were cosmetically appealing for correction of high refractive errors. ${ }^{8}$ However, these materials induce chromatic aberrations and its higher specific gravity increase the weight of these lenses. ${ }^{3}$

\section{Plastic Materials}

Plastic spectacle lenses comprise of polymers, or longchain molecules that have many interconnecting branches or crosslinks, which provide more flexibility than glass and better impact resistance. ${ }^{3}$ Although CR- $39^{\circledR}$ is often used in the manufacture of spectacle lenses, newer materials like polycarbonate and Trivex ${ }^{\circledR}$ have fewer crosslinks, and deliver a unique impact resistance. ${ }^{7}$

High refractive index plastic lenses are typically made of polyurethane resins, ${ }^{9}$ resulting in a lower density, lightweight lens material. ${ }^{7}$ A recent innovation (MR-174TM) is a bio-based, plastic high refractive index lens material that is produced using environmentally sustainable manufacturing and processing techniques. ${ }^{10}$

\section{Spectacle Lens Tints and Coatings}

Polycarbonate absorbs all ultraviolet (UV) radiation below 380 nanometers $(\mathrm{nm})$, unlike crown glass and CR-39 ${ }^{\circledR}$ which have to be treated to provide UV protection. ${ }^{3}$ The inclusion of UV absorbers also prevents the lens material from weathering and becoming brittle. ${ }^{11}$

Even though solid tinted glass lenses were already being manufactured from the mid-1600s, ${ }^{3}$ the first documented link between short-wavelength light and glare sensitivity was by Theodore-Edouard Fieuzal in 1885, with the subsequent recommendation of the use of tinted or absorptive lenses to protect the eyes from glare, and bright sunlight. ${ }^{12}$ The tinting process reduces light transmission through the lens, and controls the level of ambient sunlight while maintaining normal colour vision and 
stereopsis. ${ }^{3}$ Tints may be solid, or photochromic, that is, reversibly variable in the presence of ambient UV light and short-wavelength visible light. ${ }^{3}$

\section{Solid or Fixed Tints}

The addition of specific metallic salts to the glass mixture produces a solid tint. ${ }^{3}$ Uneven tints in high-powered lenses were later resolved by using a vacuum-coating process instead. ${ }^{3}$ In contrast, solid tinting of plastic lenses is done in a dye bath, with the dye being absorbed into the lens surface allowing for a uniform tint density. ${ }^{3}$

\section{Photochromic Tints}

Although W. Marckwald was the first to identify a solidstate organic photochromic compound in $1899,{ }^{13}$ it was only after the 1950 s that new organic and inorganic molecules were manufactured to create the photochromic effect in spectacle lenses. Glass photochromic lenses contain silver halide crystals embedded within the glass substrate. $^{3}$ In the presence of UVA light (320 to 400 $\mathrm{nm}$ ), electrons from the glass combine with the colourless silver cations to form elemental silver, resulting in a darkened appearance when activated while consequent removal of the activator results in the lens returning to a clear state. ${ }^{14}$

The first commercial plastic photochromic lens was introduced in 1982. ${ }^{14}$ The organic photochromic materials used in plastic lenses may include spiropyrans, spirooxazines, and naphthopyrans. ${ }^{14}$ High refractive index plastic materials were not readily responsive to standard photochromic dyes, until a process was developed in which spiroindoline photochromic dye was inserted between several coatings of polyurethane on the surface of polycarbonate lenses allowing for a uniform tint density across the lens. $^{3}$

Motor vehicle windscreens have an inner layer of polyvinyl butyral containing UV absorbers that prevents photochromic activation when inside the vehicle. ${ }^{15} \mathrm{~A}$ recent innovation, however, using a combination of photochromic compounds of different spectral sensitivities allows for the photochromic molecules to now activate behind a windscreen of a vehicle. ${ }^{15}$

\section{Anti-Reflective Coatings}

While the concept of an anti-reflective lens coating (ARC) was initially proposed in $1880,{ }^{16}$ the first observation of this coating in nature was in 1886 , when it was noted that tarnishing on aged ophthalmic glass allowed greater light transmission compared with new glass. ${ }^{17}$ In 1935, the Carl
Zeiss company produced the first interference-based ARC. ${ }^{17}$ Surface reflections are reduced by applying a thin film of transparent material on both lens surfaces, the thickness of which should be $1 / 4$ the wavelength of the incident light, and of a lower refractive index than the lens. ${ }^{3}$ To achieve this with crown glass material, a single thin layer of magnesium fluoride is applied to the lens surface. ${ }^{3}$

Initial challenges in the application of ARC on plastic lenses were overcome with the use of a double layer coating. Currently, multiple layers are applied on each lens surface, achieved through a physical vapour deposition technique, consisting of four-layer coatings of alternating high (either titanium oxide or zirconium dioxide) and low index (silicone dioxide) dielectric materials. ${ }^{18}$ Recently, these coatings have a blue light control filter included to circumvent concerns about over-exposure to high energy visible (HEV) light emitted from visual display units, and smartphones. ${ }^{11}$ This may be achieved either by a surface coating that inhibits the HEV light, or by incorporating a yellow absorbing dye into the material. ${ }^{11}$

\section{Scratch-Resistant Coatings}

Despite crown glass being considered a durable material, minor defects may significantly weaken it and therefore it must be tempered using heat, or chemically through an ion exchange process. ${ }^{3}$ Plastic lenses are prone to scratches therefore a scratch-resistant coating is recommended. This may be achieved by vacuum depositing a layer of silicone dioxide, ${ }^{6}$ or using a dip-or spin-coat process on the lens surface. $^{18}$

Recently multi-stack layer surface coatings were adopted. These comprise a primer coating that improves the impact resistance of the lens, a hard coating, multiple layer anti-reflective stack and a top coat. ${ }^{18}$ The top coat provides a hydrophobic property by electrostatically repelling water molecules, and an oleophobic function that prevents grease deposit formation on the lens surface. ${ }^{19}$

The major developments in the advancements in spectacle lens materials are highlighted in a timeline (Figure 1). The ideal spectacle lens material should be transparent to visible light, homogeneous, aberration-free, not be prone to warpage, have good impact resistance, easy to process, easily accepting of surface coatings and tints, and should not have an adverse reaction on the wearer. ${ }^{20}$

\section{Practical Application}

To provide an optimum lens profile when prescribing spectacles, some of the factors to consider include the 


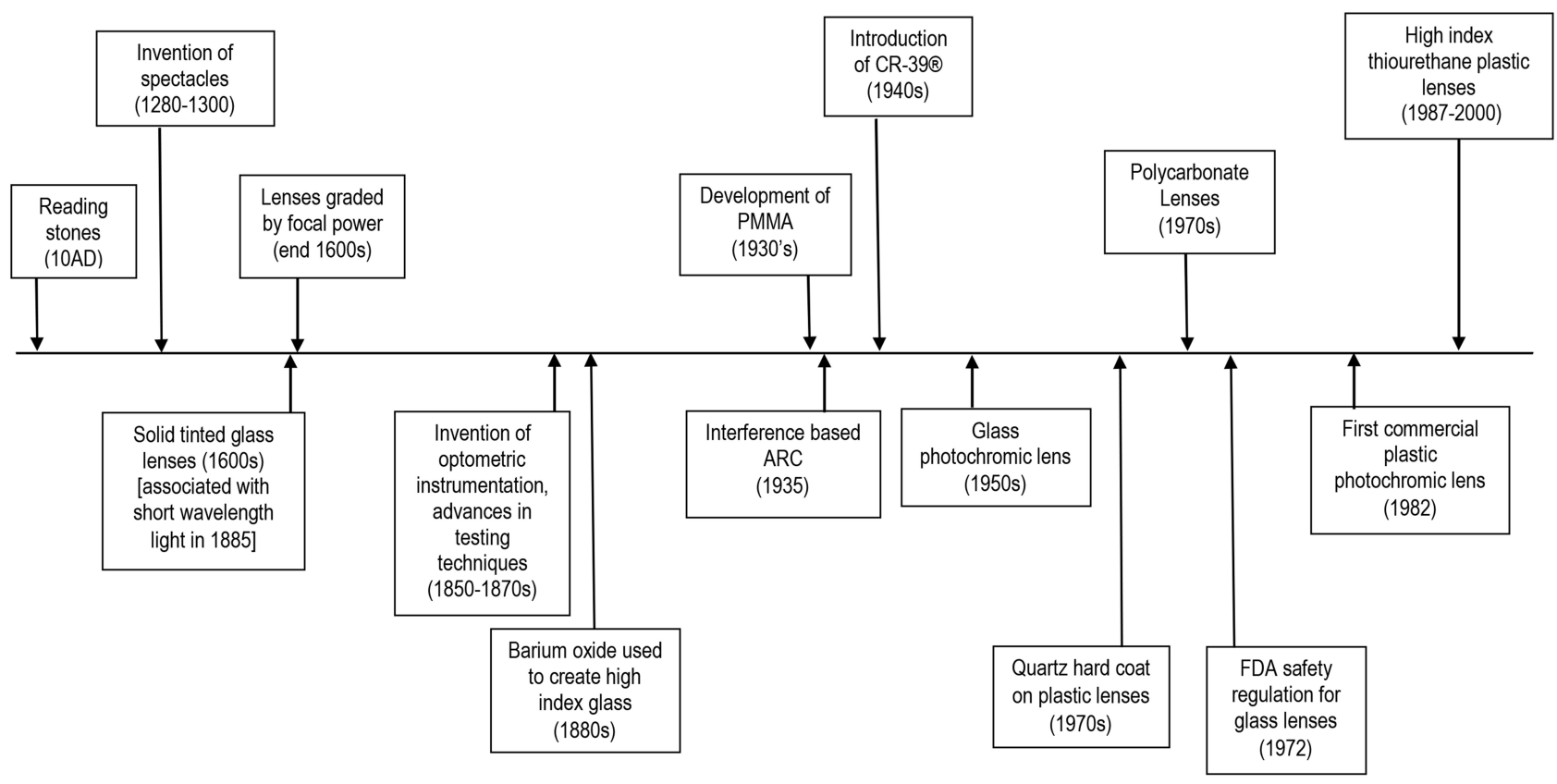

Figure I Timeline of major developments in the history of spectacle lenses.

wearer's prescription, occupation, lifestyle and budget. The choice of frame eye size and the use of custom digitalised lens technology can also improve the lens profile.

Some of the relevant terminologies that relate to the lens material includes the refractive index which describes the refraction of light when it enters the lens material. ${ }^{20}$ A higher refractive index provides more light refraction and therefore a thinner lens profile which is useful with high refractive error correction.

Specific gravity refers to the density of the material compared to that of water, with a higher specific gravity denoting a heavier lens. ${ }^{21}$ The Abbe value measures the ability of the material to disperse light, with a higher Abbe value indicating a lower likelihood of chromatic aberrations. ${ }^{21}$ Typically, a higher refractive index lens material provides a thinner lens profile but more chromatic aberrations and the flatter lens curves can increase surface reflections. ${ }^{21}$ These disadvantages can be eliminated by applying ARC on the lens surface. ${ }^{21}$ It is also important to note that surface coatings may reduce the impact resistance of a lens. ${ }^{7}$

Spectacles for occupational ocular safety and everyday use (dress spectacles) are governed by different international safety regulations..$^{21}$ Generally, high index materials, polycarbonate and $\operatorname{Trivex}^{\circledR}$ fulfils the FDA ocular safety standards. ${ }^{21}$ International standards also regulate filters for ocular protection in occupational use of lasers, and exposure to radiation or polarised light. ${ }^{21}$ A summary of some plastic lens materials, properties and benefits is described in Table 1 .

\section{Contact Lenses}

\section{Historical Development}

A contact lens (CL) is a device placed over the cornea or sclera to correct ametropia, or for ocular therapeutic purposes. The earliest concept of a CL is attributed to Leonardo da Vinci in 1508, while John Herschel was the first to accurately describe a CL device to correct an irregular cornea in $1823 .{ }^{22}$ In the late 1880 s, three people were credited with independently inventing the CL. Adolf Fick designed a "contact spectacle," Eugene Kalt fitted an afocal glass scleral shell on keratoconic eyes, while August Muller fitted the first scleral CL having a refractive power. ${ }^{22}$

Contact lenses were manufactured from glass until the introduction of PMMA in the 1930s, with the latter dominating the CL industry due to its optical clarity, good machinability, surface wettability, mechanical stability and durability. ${ }^{22}$ A hybrid CL, comprising a central optical zone made of glass with a PMMA scleral region, was developed in 1936, and soon thereafter, scleral lenses were manufactured entirely from PMMA. ${ }^{22}$

Once it was established that PMMA caused corneal hypoxia, ${ }^{22}$ newer lens materials were pursued. The first 
Table I Summary of Spectacle Lens Material Properties, ${ }^{21}$ Benefits and Recommended Use

\begin{tabular}{|c|c|c|c|c|c|}
\hline Material & $\begin{array}{l}\text { Refractive } \\
\text { Index }\end{array}$ & $\begin{array}{l}\text { Density } \\
\left(\mathrm{g} / \mathrm{cm}^{3}\right)\end{array}$ & $\begin{array}{l}\text { Abbe } \\
\text { Number }\end{array}$ & Benefits & Recommended Use \\
\hline \multicolumn{6}{|c|}{ NORMAL INDEX (I.49-I.5) } \\
\hline CR-39 ${ }^{\circledR}$ & 1.498 & 1.32 & 58 & $\begin{array}{l}\text { Widely used due to affordability, relative to } \\
\text { glass it is lightweight and some impact } \\
\text { resistance, available in fixed or } \\
\text { photochromic tints and ARC }\end{array}$ & $\begin{array}{l}\text { Typically for refractive error correction } \\
\text { less than } 3 \text { dioptres and dress eyewear } \\
\text { when lens thickness, weight or ocular } \\
\text { safety is not a major consideration }\end{array}$ \\
\hline \multicolumn{6}{|c|}{ MID INDEX (I.54-I.6) } \\
\hline Trivex $^{\circledR}$ & 1.527 & 1.11 & 44 & Impact resistance, light weight, inherent & For children, monocular individuals, \\
\hline Polycarbonate & 1.586 & 1.22 & 30 & $\begin{array}{l}\text { UV protection, available in fixed or } \\
\text { photochromic tints and ARC }\end{array}$ & $\begin{array}{l}\text { sporting activities, ocular safety purposes, } \\
\text { use in rimless frames }\end{array}$ \\
\hline MR-8 $8^{\mathrm{TM}}$ & 1.592 & 1.3 & 41 & $\begin{array}{l}\text { Thinner lens profile, available in fixed or } \\
\text { photochromic tints and ARC }\end{array}$ & $\begin{array}{l}\text { Typically for refractive error correction } \\
\text { above } 3 \text { dioptres, use in rimless frames }\end{array}$ \\
\hline \multicolumn{6}{|c|}{ HIGH INDEX (above I.64) } \\
\hline MR-I0TM & 1.661 & 1.37 & 32 & Thinner lens profile, available in & Typically for refractive error correction \\
\hline MR-I $74^{\mathrm{TM}}$ & 1.732 & 1.47 & 33 & photochromic tints and ARC & above 3 dioptres, use in rimless frames \\
\hline
\end{tabular}

gas permeable (GP) lens using cellulose acetate was developed in 1937 but was unsuccessful due to poor manufacturing quality. ${ }^{22}$ Silicone elastomers, developed between the mid-1960s to early 1970s had better oxygen permeability but also had poor wettability, high risk of deposit formation and high processing costs. ${ }^{22}$ Cellulose acetate butyrate, introduced in 1974, was less rigid than PMMA but had low oxygen permeability, poor wettability and warped easily. ${ }^{22}$

\section{Gas Permeable Materials}

In the late 1970s, silicone was incorporated into the PMMA structure creating a new generation of commercially successful GP lens materials called silicone acrylate (SA). ${ }^{23}$ The silicone-containing side branches allowed for oxygen transfer, and although it improved oxygen permeability, it is also hydrophobic and resulted in dry, itchy and hyperaemic eyes. ${ }^{23}$ High oxygen-permeable SA lens materials often had increased lens surface deposits, warpage, crazing and brittleness. ${ }^{23}$

Further enhancements included the addition of elements like styrene and fluorine to the SA polymer to improve biocompatibility, eventually resulting in the fluoro-silicone acrylate (FSA) material in $1987 .^{23}$ These materials have a reduced silicone content but higher levels of oxygen permeability, along with the cross-linking of polymers to prevent lens flexure. ${ }^{23}$ This also improved deposit resistance, wettability, and enhanced wearer comfort, and as it is more dimensionally stable than SA materials, it is the material of choice in new GP lens fits. ${ }^{23}$ Gas permeable CL are used in correction for keratoconus, high astigmatism, and in orthokeratology as a form of myopia control. ${ }^{23}$

\section{Soft Contact Lens Materials}

In the late 1950s, Otto Wichterle and Drashoslav Lim developed a material called hydroxyethyl methacrylate (HEMA), which was biologically inert and compatible with human tissue. ${ }^{24} \mathrm{~A}$ chance meeting with an ophthalmologist resulted in Wichterle pursuing the development of a soft CL. ${ }^{22}$ By 1961, Wichterle submitted a patent for a spin-cast method of manufacturing soft CLs (called hydrogel lenses) that revolutionized the CL industry. ${ }^{25}$ Bausch and Lomb acquired this patent, and the Soflens ${ }^{\circledR}$ CL was introduced worldwide in $1972 .^{26}$

The FDA approved a hydrogel-extended wear modality CL in 1981; however, the subsequent increase in ocular complications resulted in extended wear being limited to six consecutive nights, diminishing the appeal of these CL. ${ }^{26}$ Prior to the 1980 s, patients wore the same pair of CL until these were damaged or lost. The ocular consequences thereof led to the introduction of frequent replacement lenses, with Johnson and Johnson releasing the first weekly replacement disposable CL in 1988, and the first daily disposable CL in $1994 .{ }^{26}$

The introduction of silicone hydrogel ( $\mathrm{SiHy}$ ) materials, in the late 1990s, was heralded "the most significant 
advance in CL material technology" since the development of HEMA. ${ }^{26}$ This new material was the culmination of years of research into increasing oxygen permeability without negatively affecting other material properties. ${ }^{23}$ By combining silicone with conventional hydrogel monomers, the silicone element provides increased oxygen permeability, and the hydrogel component enables fluid transport and lens movement. ${ }^{23}$

The most recent material development is a daily disposable soft CL which combines the properties of SiHy and HEMA materials. ${ }^{26}$ The water content and modulus change from the silicone core to the HEMA surface thus providing a higher oxygen permeability with a hydrophilic surface. ${ }^{26}$

The current generation of hybrid scleral design lenses has a central high oxygen permeable FSA optical zone, surrounded by a HEMA or SiHy scleral skirt. ${ }^{23}$ Newer FSA materials that incorporate HEMA, known as "modified FSA," have been developed which further improve surface wettability and wearer comfort. ${ }^{23}$

\section{Tinting of Contact Lenses}

Contact lenses may be tinted for various reasons, as a handling tint to enhance the visibility of the lens, a cosmetic tint to change or enhance iris colour, a prosthetic tint to mask visible deformity on the anterior eye or a therapeutic tint to treat an underlying defect or disease. $^{26}$

The process of tinting GP and soft CL are slightly different, with GP lenses being tinted either by adding the dye to the monomer mixture prior to polymerization, or by adding the dye to the polymer and then mixing to disperse the colour. $^{26}$ A finished soft lens may be soaked in a water-soluble dye, or in a dye solution in the presence of a catalyst, for a fixed time period at a particular temperature, or the tint may be printed onto the lens material itself. ${ }^{26}$ A recent development is a photochromic tinted soft CL material, in which the photochromic properties may be created by the inclusion of polymerisable chromenes, spiropyrans, or oxazines, amongst others. $^{27}$

Ultraviolet radiation blocking monomers may be incorporated into the material matrix in both GP and soft CL materials. However, the UV-blocking capacity of CL materials is inadequate and UV filtering sunglasses are recommended with $\mathrm{CL}$ wear. ${ }^{26}$

The ideal contact lens material should be safe, inert, biocompatible, non-toxic, and comfortable on the eye, allow $100 \%$ transmission of light, provide clear, stable vision, permeable to oxygen and ions, meet or exceed corneal oxygen requirements, be durable, chemically and mechanically stable with good wettability, deposit resistant with adequate water content and be easy to process with a low manufacturing cost and able to filter $\mathrm{UV}^{23}$

A timeline of the major developments (Figure 2) illustrates the progress from the original glass scleral CL to the current SiHy lenses which was achieved in a remarkably short period of time, reflecting the advances in material technology. With comfort being a major factor, soft CL fits accounted for $87 \%$ of contact lens fits worldwide in 2019 , and of which $72 \%$ were SiHy materials. ${ }^{28}$

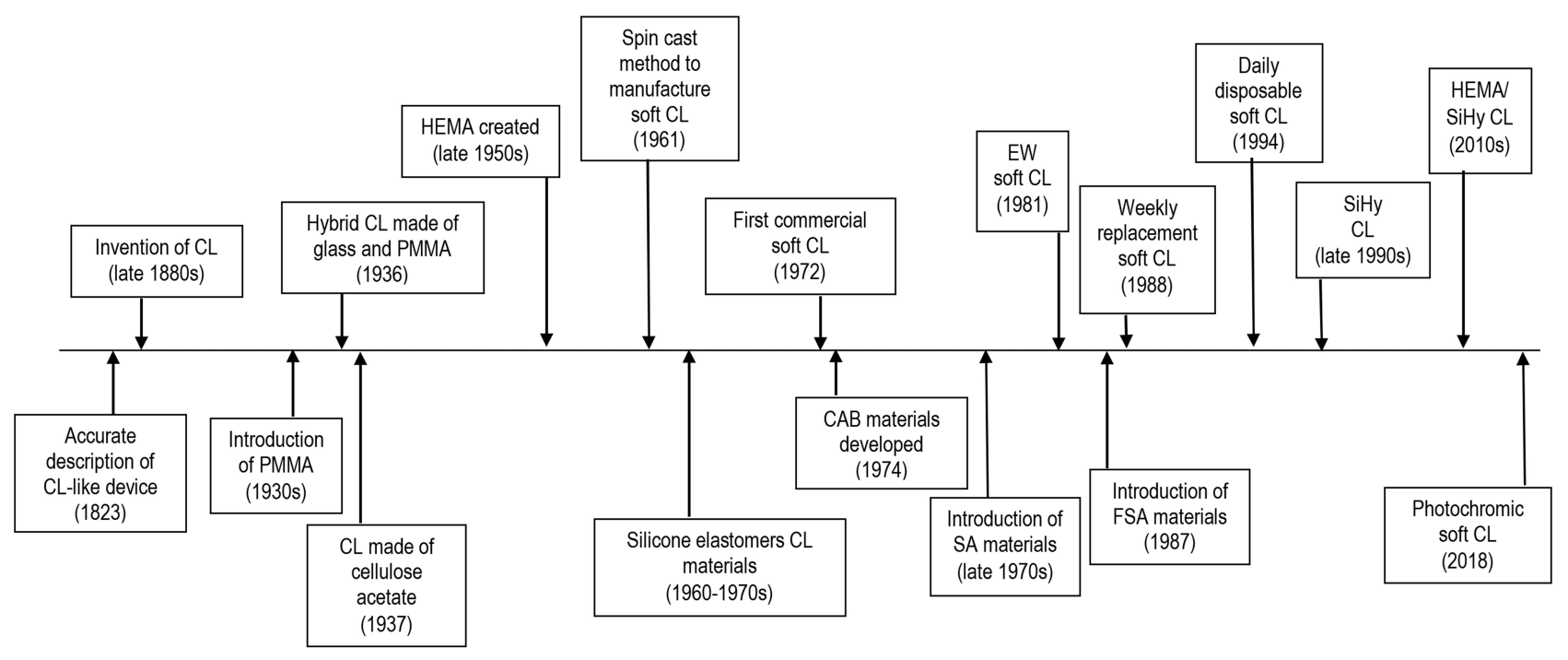

Figure $\mathbf{2}$ Timeline of major developments in the history of contact lenses. 


\section{Practical Application}

When prescribing CL, there are many factors to be considered, including occupational and lifestyle needs of the wearer, use of digital devices, and type of work environment. For patients who participate in sporting activities, knowledge of the environmental conditions is required, that is, exposure to dust, water, temperature, altitude, UV, as well as body movement and contact involved in that sport. ${ }^{26}$ Also consider convenience, ease of use, handling capability and budget of the wearer, so a thorough case history is essential.

It is also important to note that although the material formulation, CL design and form are vital, the ocular health of the wearer and ocular surface conditions, like dry eye disease, will impact on CL performance. Although $\mathrm{CL}$ wear is not a total contraindication for a monocular patient, it is vital that the eye care practitioner discusses and documents the risks and benefits of CL wear with the patient. ${ }^{29}$ Factors that should be considered include the age, refractive error, occupation, lifestyle, sporting activities and systemic health of the individual. ${ }^{29}$ Consider a SiHy daily disposable CL with spectacles made of polycarbonate or Trivex ${ }^{\circledR}$ materials for sporting activities if the monocular patient decides to proceed with CL wear. ${ }^{29}$

Some of the practical considerations when selecting CL materials are briefly described, followed by the current classification of CL materials.

\section{Oxygen Permeability and Transmissibility}

Oxygen permeability (Dk) is an inherent material property, referring to the amount of oxygen that can diffuse through the material, and a high value indicates that more oxygen will pass through the material. ${ }^{23}$ Oxygen Transmissibility $(\mathrm{Dk} / \mathrm{t})$ is a function of lens thickness, shape and vertex power and refers to the amount of oxygen that will diffuse through a CL of specified thickness. ${ }^{23}$ The oxygen transmissibility criteria by Holden and Mertz, to avoid corneal oedema, is 24.1 Barrer for daily wear and 87 Barrer for overnight wear of CL. ${ }^{30}$

\section{Water Content}

This property is especially important in hydrogel CL as oxygen is able to diffuse through water. ${ }^{23}$ Oxygen permeability increases with an increase in water content; however, this reduces the refractive index of the material, and consequently affects the lens thickness. ${ }^{23}$ Silicone hydrogel CL can have a lower water content than hydrogels as the oxygen permeability of SiHy material is not dependent on water content but on the silicone component. ${ }^{23}$

\section{Refractive Index}

Fluorosilicone acrylate lenses usually have a refractive index between 1.420 and 1.460 , while SA materials often have a refractive index of 1.460 or greater. ${ }^{23}$ Refractive index is not always a deciding factor in the choice of rigid lens material unlike with spectacle lens dispensing. ${ }^{23}$ Some manufacturers have designed multifocal GP lenses with newer high index materials to enhance reading add. ${ }^{23}$

\section{Surface Wettability}

Good surface wettability can help create a stable tear film over the lens surface which may help improve lens comfort, vision and reduce resistance to deposits. ${ }^{23}$ This may be achieved by the use of a plasma coating or plasma oxidation surface treatment, an internal wetting agent like polyvinyl pyrrolidone (PVP) or incorporation of inherent wettable silicone-based macromers into the lens matrix. ${ }^{26}$ Surface wettability may be improved by creating specific lens solutions for SiHy materials or incorporation of PVP in the solution of the lens blister pack. ${ }^{26}$ Hydrophilic polyethylene glycol polymer coatings, which can be applied to any CL material, improve surface wettability, deposit resistance, and thereby enhances wearer comfort. ${ }^{31}$

\section{Lens Modulus}

This describes the ability of the material to resist deformation. ${ }^{23}$ Although a high modulus material would be stiffer, better at retaining its shape, and easier to handle, it may also cause lens fluting, superior epithelial arcuate lesions, or giant papillary conjunctivitis. ${ }^{23}$ Most silicone hydrogel materials have a lens modulus greater than hydrogel materials. ${ }^{23}$

\section{Surface lonic Charge}

Some CL materials are referred to as ionic, due to the presence of an electric charge caused by its chemical formulation. ${ }^{23}$ Typically, an overall negative charge can cause dimensional changes in the lens, material degradation or protein deposit formation from tear film constituents. ${ }^{23}$ Materials that are electrically neutral, or non-ionic, are more inert and deposit resistant. ${ }^{23}$

\section{Lipid Deposits}

Silicone is intrinsically lipophilic due to its hydrophobic nature therefore SiHy lenses tend to attract lipid deposits 
from the tear film constituents, whereas this is not a major concern with hydrogel lenses. ${ }^{23}$

\section{Replacement Frequency}

Although the FDA approves CLs to be worn for either Daily Wear (DW) or Extended Wear (EW), it is important to note that the $\mathrm{CL}$ replacement schedule is a recommendation by the manufacturer to guide lens performance, and patient ocular comfort and health. ${ }^{23}$

With DW, a set of CLs is recommended to be used during the day and removed before sleep for a certain interval before disposal. ${ }^{26}$ Planned replacement of DW CLs may include a time period of daily, 2-weekly, monthly, 3-monthly, 6-monthly or annual CL replacement. ${ }^{26}$

Generally, EW refers to CLs worn for a maximum of 7 days and 6 nights uninterrupted before removal while continuous wear (CW) may refer to $\mathrm{CL}$ approved for 30 nights of continuous wear before replacement. ${ }^{26}$ Although there are a few SiHy CL that are approved for CW, including Air Optix Aqua ${ }^{\circledR}$, Acuvue Oasys ${ }^{\circledR}$, Biofinity ${ }^{\circledR}$, the only GP lens that is FDA-approved for 30-day $\mathrm{CW}$ is Menicon $\mathrm{Z}^{\circledR .23}$

\section{UV Classification}

Silicone Hydrogel CL that offer UV protection are labelled as Class I or Class II, with the former blocking $90 \%$ of UVA (316-400nm) and 99\% of UVB (280-315nm) while the latter must block at least $70 \%$ of UVA and $95 \%$ of UVB radiation. ${ }^{32}$ Non-UV blocking CLs have been recorded to absorb approximately $10 \%$ of UVA and $30 \%$ of UVB, ${ }^{32}$ so sunglasses with full UV-blocking properties are recommended for $\mathrm{CL}$ wear. ${ }^{26}$

\section{Material Classification}

A few CL material classifications exist, including that of the FDA, and the International Organization for Standardization (ISO). All CL materials are allocated a non-proprietary name by the US Adopted Name Council (USAN). ${ }^{33}$ These generic names comprise a prefix, stem and suffix. ${ }^{33}$ The prefix is finalised by USAN based on the chemical formulation of the CL material while the stem is decided by the water content of the material. ${ }^{33}$ If less than $10 \%$ water by mass is present then the stem -focon (non-hydrogel or rigid CL) is used, and if the material has $10 \%$ or more water by weight then the stem -filcon (hydrogel CL) is used. ${ }^{33}$ The series suffix, in alphabetic format also governed by the USAN, indicates if revisions were made to material formulation, with A being the original material and $\mathrm{B}$ the revised material, and so on. ${ }^{33}$

The FDA classification, created for the purpose of testing the interaction between $\mathrm{CL}$ and care products, groups together soft $\mathrm{CL}$ materials of similar water content and ionic surface properties ${ }^{26}$ (Table 2).

The ISO classification for CL materials is a 7-part code found in the standard BS EN ISO 18369:2017. ${ }^{34}$ The first three parts of this code comprises a prefix, stem, and series suffix adopted by $\mathrm{USAN}^{33}$ as described above. This is followed by a group suffix in Roman numerals that describes the material as either from the -focon (Table 3) or-filcon group (as described in the FDA classification for soft CL materials in Table 2). The $\mathrm{Dk}$, water content and modification codes comprise the last three parts of the ISO classification. A modification code denoted by a specific lower case alphabet indicates that the lens surface is different from the bulk characteristics of the material. ${ }^{34}$ For filcon groups I-IV, " $\mathrm{m}$ " indicates a surface plasma

Table 2 FDA Classification of Soft CL Materials for Lens-Solution Interaction Testing

\begin{tabular}{|c|c|c|c|}
\hline Group & Characteristics & Example of Lens & Comments \\
\hline I & $\begin{array}{l}\text { Low Water }\left(<50 \% \mathrm{H}_{2} \mathrm{O}\right) \\
\text { Nonionic Hydrogel }\end{array}$ & Polymacon (38\%) $(\mathrm{Dk}=9)$ & $\begin{array}{l}\text { Lowest rate of protein deposit formation of hydrogel materials } \\
\text { due to non-ionic surface properties. low } \mathrm{Dk}\end{array}$ \\
\hline II & $\begin{array}{l}\text { High Water }\left(>50 \% \mathrm{H}_{2} \mathrm{O}\right) \\
\text { Nonionic Hydrogel }\end{array}$ & Omafilcon B $(62 \%)(\mathrm{Dk}=34)$ & $\begin{array}{l}\text { Heat disinfection, preservatives sorbic acid and potassium } \\
\text { sorbate should be avoided }\end{array}$ \\
\hline III & $\begin{array}{l}\text { Low Water }\left(<50 \% \mathrm{H}_{2} \mathrm{O}\right) \\
\text { lonic Hydrogel }\end{array}$ & Deltafilcon A (43\%) $(\mathrm{Dk}=10)$ & $\begin{array}{l}\text { Higher rate of protein deposit formation due to ionic surface } \\
\text { properties. low Dk }\end{array}$ \\
\hline IV & $\begin{array}{l}\text { High Water }\left(>50 \% \mathrm{H}_{2} \mathrm{O}\right) \\
\text { lonic Hydrogel }\end{array}$ & Etafilcon A (58\%) (Dk = 28) & $\begin{array}{l}\text { Highest rate of protein deposit formation of all groups. Heat } \\
\text { disinfection, preservatives sorbic acid and potassium sorbate } \\
\text { should be avoided }\end{array}$ \\
\hline V & Silicone Hydrogel & Lotrafilcon B (33\%) $(\mathrm{Dk}=1 \mathrm{I} 0)$ & $\begin{array}{l}\text { Soft materials that have a Dk value greater than } 30 \text {, which is } \\
\text { not explained by their water content }\end{array}$ \\
\hline
\end{tabular}


Table 3 Characteristics of the -focon Group

\begin{tabular}{|l|l|l|l|}
\hline Group & Characteristics & Example of Lens & Comments \\
\hline I & $\begin{array}{l}\text { Contains no silicone } \\
\text { or fluorine }\end{array}$ & $\begin{array}{l}\text { Cellulose Acetate } \\
\text { Butyrate }\end{array}$ & $\begin{array}{l}\text { More flexible, less brittle compared to PMMA. Low Dk compared to currently available } \\
\text { materials. Was considered for special cases where 3 and 9 o'clock staining was a } \\
\text { problem. Not used currently. }\end{array}$ \\
\hline II & $\begin{array}{l}\text { Contains silicone (no } \\
\text { fluorine) }\end{array}$ & Silicone Acrylate & $\begin{array}{l}\text { Silicone improves the Dk, but its inherent hydrophobicity may result in lipid and protein } \\
\text { deposits. Available in a range of low to medium Dk and has good scratch resistance. } \\
\text { Commonly used are the Boston II and Boston IV, and Paraperm O2, and Paraperm EW. }\end{array}$ \\
\hline III & $\begin{array}{l}\text { Contains silicone and } \\
\text { fluorine }\end{array}$ & $\begin{array}{l}\text { Fluorosilicone } \\
\text { Acrylate }\end{array}$ & $\begin{array}{l}\text { Fluorine increases deposit resistance, also higher Dk's are possible. Increased wettability } \\
\text { improves patient comfort. Low Dk materials are typically the lens of choice for most } \\
\text { myopic DW patients while high Dk materials is preferable for hyperopes and for EW or } \\
\text { CW. Examples include the FluoroPerm range and Menicon Z. }\end{array}$ \\
\hline IV & $\begin{array}{l}\text { Contains fluorine (no } \\
\text { silicone) }\end{array}$ & Fluorocarbon & $\begin{array}{l}\text { Contains methyl methacrylate. High fluorine content increases Dk/t and lens flexibility. It } \\
\text { had limited popularity regardless of good wettability and deposit resistance. }\end{array}$ \\
\hline
\end{tabular}

Note: Data from these studies. ${ }^{23,26}$

treatment. ${ }^{34}$ Whereas in -filcon group V, "c" indicates a chemically modified surface, and " $\mathrm{w}$ " may be used for materials having internal wetting agents. ${ }^{34}$

The list of available CL is extensive and some useful resources for eye care practitioners with searchable database on current soft and GP CLs can be found at:

i) Contact Lens Compendium: https://compendium.con tactlensupdate.com/ca/contact_lens/search

ii) GP Lens Institute: https://www.gpli.info/materials/

\section{The Future}

Numerous concepts using prototype materials have been proposed to aid in vision correction, as outlined below.

\section{Adaptive Lenses}

These lenses correct refractive error by reversibly altering either the refractive index or lens shape. ${ }^{35}$ Liquid crystal (LC) designs combine properties of both crystalline solids and liquids, ${ }^{35}$ and have received much attention especially in the correction of presbyopia. ${ }^{36}$ In its solid state, the LC molecules are in regular order and held in fixed positions. ${ }^{35}$ Upon application of a controlled electrical current, the LC molecules rotate into a liquid formation thus changing the refractive index and therefore the focal length. ${ }^{35}$

Liquid crystal spectacle lenses have a default distance vision correction, and by touching a sensor on the temple, the LC section of the lens (lower nasal aspect) becomes an active reading prescription. ${ }^{37}$ This is powered by a rechargeable battery on the temple tip. ${ }^{37}$ Using this technology, a manufacturer has commercialized "omnifocals," which are lenses that have an LC layer between two layers of indium tin oxide-coated glass. ${ }^{38}$ Infrared sensors on the frame measure and transmit information about the wearer's inter-pupillary distance to an embedded processing unit. ${ }^{38}$ An electric current then rearranges the LC molecules so that vision is corrected appropriately to the distance being viewed. ${ }^{38}$ This lens provides a full field of view for reading unlike that of progressive addition lens designs. ${ }^{38}$

In LC sunglasses, the lens colour changes according to the ambient conditions when a sensor on the frame is activated. $^{39}$ This serves to protect the wearer against both short and long-wavelength visible light. ${ }^{39}$

A prototype LC CL made of PMMA was developed to correct presbyopia although recent investigations centre on using hydrogel materials with an embedded LC layer. ${ }^{36}$ Switching from distance to near vision requires external electronics, possibly wireless technology, using blink detection or proximity sensors that track eye convergence, or change in pupil size during convergence as possible approaches for inducing the change in the refractive power. $^{36}$

\section{Metalenses}

The metalens prototype is a planar lens, approximately one micron in thickness, with neither refractive nor diffractive properties. ${ }^{40}$ Rather than using a homogeneous glass or polymeric material, this prototype lens has millions of "nanopillars" made of titanium dioxide, that are custom arranged on a single surface to bend the light spectrum to correct ametropia. ${ }^{40}$ With proposed improvements to the 
perceived light spectrum (currently 490 to $550 \mathrm{~nm}$ ) and resolution of images, it is possible the unsightly bulky lenses required for correction of high ametropia may be relegated to museums.

\section{Three Dimensional Printing}

Additive manufacturing, or three dimensional (3D) printing, refers to the creation of a 3D object, based on a computer-aided design, that is printed in a structured layer-by-layer technique. ${ }^{41}$ Traditionally spectacle lenses are cut and processed to specification from a semi-finished blank, resulting in non-recyclable waste products. ${ }^{42}$ Lens blanks are usually mass produced and transported from different countries of origin which further increases the carbon footprint of the product. Recently a spectacle lens manufacturer has incorporated a 3D print platform into an ophthalmic laboratory setting. ${ }^{42}$ The custom-designed lenses are printed on demand, requiring few hours for the finished product, negating the need for stock-on-hand while reducing waste, water and energy consumption. ${ }^{42}$

The field of 3D printing has many potential ophthalmic applications, including tailor-made spectacles for patients with facial deformities, ${ }^{43}$ and custom-design 3D printed corneas. ${ }^{41}$ A recent prototype $3 \mathrm{D}$ printed CL that corrects refractive error has embedded polarising filters to mitigate seizures in patients with photosensitive epilepsy. ${ }^{44}$

\section{Lenses for Ocular Drug Delivery}

New CL materials for ocular drug delivery are being investigated, including a double-network, interpenetrating hydrogel, that combines yet retains the individual properties of the two selected hydrogels. ${ }^{45}$ Temperature- and pH-responsive lens materials alter their conformation upon exposure to oneye temperature or $\mathrm{pH}$, thereby allowing for the release of the embedded or encapsulated drug into the eye. ${ }^{45}$ A patent was granted for an iontophoretic CL in which electrically charged therapeutic molecules are non-invasively propelled into the anterior or posterior chamber of the eye, potentially eliminating the need for intrusive ocular injections used for some chronic retinal conditions and selected macular oedema. ${ }^{46}$

\section{Biomimetic Lens}

A prototype $\mathrm{CL}$ was developed in which electrooculogram (EOG) signals, generated by eye movements, prompt activation of the lens. ${ }^{47}$ It is anticipated that this lens design, comprising of electroactive dielectric elastomer films, PMMA and polyethylene terephthalate materials, could be used in the manufacture of visual prostheses, or allow automatic adjustable-focus for distance and near vision through a double blink mechanism, or be used to remotely control soft robotics via EOG signals. ${ }^{47}$

\section{Conclusion}

Since the days of the travelling spectacle peddlers, the approaches to vision correction have progressed immensely. This includes advances in the materials and manufacturing processes used to produce spectacle lenses and contact lenses. Considering the significant developments over the past half-century, it is anticipated that emerging technologies will play a vital role in the way in which vision is corrected in the future.

\section{Disclosure}

This article forms part of a $\mathrm{PhD}$ study in the Discipline of Optometry at the University of KwaZulu-Natal (Ethics approval: HSS/1649/018D) being undertaken by RP with $\mathrm{RH}$ and NR as the supervisors. The authors report no funding and no conflicts of interest for this work.

\section{References}

1. World Health Organization. International classification of diseases 11th revision; 2018. Available from: http://www.who.int/classifica tions/icd/en/. Accessed November 9, 2019.

2. Flaxman SR, Bourne RRA, Resnikoff $S$, et al. Global causes of blindness and distance vision impairment 1990-2020: a systematic review and meta-analysis. Lancet Glob Health. 2017;5:e1221-e1234. doi:10.1016/S2214-109X(17)30393-5

3. Benjamin WJ. Borish's Clinical Refraction. 2nd ed. St. Louis: Butterworth-Heinemann; 2006.

4. Rubin M. Spectacles: past, present, and future. Surv Ophthalmol. 1986;30(5):321-327. doi:10.1016/0039-6257(86)90064-0

5. Colenbrander A. Measuring vision and vision loss. Duane's Clin Ophthalmol. 2006;5.

6. Bruneni J More than meets the eye. The stories behind the development of plastic lenses. 1997. Available from: http://www.ppgoptical. com/getmedia/47e39594-6472-48e7-8e2c-8f48015284c8/CR39_ 50years_booklet.pdf. Accessed May 22, 2019.

7. Brooks CW, Borish IM. System for Ophthalmic Dispensing. 3rd ed. St Louis: Butterworth-Heinemann; 2007.

8. Faulstich M, Geiler V, Gliemeroth G, inventors; Jenaer Glaswerk Schott and Gen, assignee. High refractive index glasses of limited specific gravity for distance and near vision spectacle lenses. United States patent US 4213787A. 1978 Jun 7.

9. Kagei K, Kobayashi T, inventors; Asahi Lite Optical Co Ltd, assignee. Plastic lenses for spectacles with high refractive indices. United States patent US 6070979A. 1995 Oct 24.

10. Mitsui Chemicals Inc. Development of plant-derived high refractive index lens material "Do GreenTM"; 2015. Available from: https://jp. mitsuichemicals.com/en/release/2015/150129.htm. Accessed June 28, 2019.

11. Carrega A, Jimenez A, Lestournelle F, Kudla A, inventors; Essilor International, assignee. Optical article protecting from blue light. International patent. WO 2017077357A1. 2015 Nov 06.

12. Fieuzal T. Des verres colorés, en hygiene oculaire. [Colored glasses, in eye hygiene]. Société de Médicine Publique; 1885. [French]. 
13. Marckwald W. Üeber Phototropie. [About phototrophy]. Z Phys Chem. 1899;30:140-145. doi:10.1515/zpch-1899-3007

14. Crano JC, Flood T, Knowles D, Kumar A, Van Gemert B. Photochromic compounds: chemistry and application in ophthalmic lenses. Pure Appl Chem. 1996;68(7):1395-1398. doi:10.1351/ pac199668071395

15. Ambler DM, Balch TA, Yamasaki N, inventors; Younger Mfg Co, assignee. Eyewear lens having selective spectral response. United States patent US 6926405B2. 2003 Jun 6.

16. Rayleigh L. On reflection of vibrations at the confines of two media between which the transition is gradual. Proc London Math Soc. 1879;s1-s11(1):51-56. doi:10.1112/plms/s1-11.1.51

17. English N. Classic Telescopes: A Guide to Collecting, Restoring, and Using Telescopes of Yesteryear. 1st ed. New York: Springer-Verlag; 2013

18. Samson F. Ophthalmic lens coatings. Surf Coat Tech. 1996;81:79-86. doi:10.1016/0257-8972(95)02532-4

19. Santan PD, Tarleton NM, inventors; Signet Armorlite Inc, assignee. Surface modification of hydrophobic and/or oleophobic coatings. United States patent US 8691331B2. 2009 Feb 9.

20. Fowler C. Spectacle Lenses: Theory and Practice. 1st ed. Oxford: Butterworth-Heinemann; 2001.

21. Alonso J, Gómez-Pedrero JA, Quiroga JA. Modern Ophthalmic Optics. Cambridge: Cambridge University Press; 2019.

22. Mandell R. Contact Lens Practice. 4th ed. Illinois: Charles C Thomas Publisher; 1988.

23. Bennett ES, Henry VA. Clinical Manual of Contact Lenses. 4th ed. Philadelphia: Lippincott Williams \& Wilkins; 2014.

24. Wichterle O, Lim D. Hydrophilic gels for biological use. Nature. 1960;185:117-118. doi:10.1038/185117a 0

25. Wichterle O, inventor; The Cezch Academy of Science, assignee. Method of manufacturing soft and flexible contact lenses. United States patent US 3496254A. 1965 Jul 1.

26. Efron N. Contact Lens Practice. 3rd ed. Edinburgh: Elsevier Ltd; 2018.

27. Gemert B, Kumar A, Mallak F, Walters R, inventors; Transitions Optical Inc, assignee. Photochromic contact lenses and methods of manufacturing. United States patent US 20030142267A1. 2002 Dec 10.

28. Morgan PB, Woods CA, Tranoudis IG, et al. International contact lens prescribing in 2019; 2020. Available from: http://www.clspec trum.com/issues/2020/january-2020/international-contact-lensprescribing-in-2019. Accessed January 12, 2020.

29. Schornack M. Prescription and management of contact lenses in patients with monocular visual impairment. Optometry. 2007;78 (12):652-656. doi:10.1016/j.optm.2007.02.022

30. Holden BA, Mertz GW. Critical oxygen levels to avoid corneal oedema for daily and extended wear contact lenses. Invest Ophthalmol Vis Sci. 1984;25:1161-1167.

31. Sindt CW. Tangible ${ }^{\mathrm{TM}}$ Hydra-PEG: a novel custom contact lens coating technology designed to improve patient comfort and satisfaction; 2016. Available from: https:/www.eye-iq.com/uploads/ Hydra-PEG-White-Paper.pdf. Accessed April 19, 2020.
32. Rahmania S, Niaa MM, Baghbanb AA, Nazaria MR, GhassemiBroumanda M. Spectral transmittance of UV-blocking soft contact lenses: a comparative study. Cont Lens Anterior Eye. 2014;37:451-454. doi:10.1016/j.clae.2014.07.011

33. American Medical Association. United States Adopted Name: contact Lenses 2019. Available from: https://www.ama-assn.org/about/ united-states-adopted-names/contact-lenses. Accessed April 19, 2020.

34. International Organization for Standardization. BS EN ISO 18369-1:2017. Ophthalmic Optics. Contact Lenses - Part 1: vocabulary, classification system and recommendations for labelling specifications. 2017 Jan 01.

35. Algorri JF, Zografopoulos DC, Urruchi V, Sánchez-Pena JM. Recent advances in adaptive liquid crystal lenses. Crystals. 2019;9(5):272. doi: $10.3390 /$ cryst 9050272

36. Bailey J, Morgan PB, Gleeson HF, Cliff Jones J. Switchable liquid crystal contact lenses for the correction of presbyopia. Crystals. 2018;8(1):29. doi:10.3390/cryst8010029

37. Okada $T$, Nakamura $T$, Nishioka $K$, Yamamoto $H$, Kouchi $T$, Tomabechi H, inventors; Olympus Corp, assignee. Liquid crystal spectacles. United States US 4756605A. 1986 Jan 21.

38. Deep Optics. Omnifocals; 2017. Available from: http://www.deepop tics.com/do site/. Accessed November 9, 2019.

39. Black M, Kupershmidt V, inventors; Reliant Technologies LLC, assignee. Liquid crystal sunglasses with selectively color adjustable lenses. United States patent US 5114218A. 1991 Jan 11.

40. MacInnis B. Metalens ophthalmic devices: the new world of optics is flat. Can J Ophthalmol. 2018;53:91-93. doi:10.1016/j.jcjo.2018.02. 001

41. Sommer AC, Blumenthal EZ. Implementations of 3D printing in ophthalmology. Graefes Arch Clin Exp Ophthalmol. 2019;257:1815-1822. doi:10.1007/s00417-019-04312-3

42. Luxexcel Group. Ophthalmic products; 2019. Available from: http:// www.luxexcel.com/ophthalmic-technology/ophthalmic-lenses. Accessed November 9, 2019.

43. Ayyildiz O. Customised spectacles using 3-D printing technology. Clin Exp Optom. 2018;101(6):747-751. doi:10.1111/cxo.12795

44. Haria R Student to commercialize anti-epilepsy contact lenses using 3D printing; 2017. Available from: http://www.3dprintingindustry. com/news/student-commercialize-anti-epilepsy-contact-lenses-using -3d-printing-126171/. Accessed October 2, 2019.

45. Musgrave CSA, Fang F. Contact lens materials: a materials science perspective. Materials. 2019;12(2):261. doi:10.3390/ma12020261

46. Manzo M, inventor; Eyegate Pharmaceuticals Inc, assignee. Iontophoretic contact lens. International patent WO 2016118933A1. 2016 Jan 22.

47. Li J, Wang Y, Liu L, Xu S, Liu Y, Leng J. A biomimetic soft lens controlled by electrooculographic signal. Adv Funct Mater. 2019;29 (36). doi:10.1002/adfm.201903762
Clinical Optometry

\section{Publish your work in this journal}

Clinical Optometry is an international, peer-reviewed, open access journal publishing original research, basic science, clinical and epidemiological studies, reviews and evaluations on clinical optometry. All aspects of patient care are addressed within the journal as well as the practice of optometry including economic and business analyses. Basic and clinical research papers are published that cover

Submit your manuscript here: https://www.dovepress.com/clinical-optometry-journal all aspects of optics, refraction and its application to the theory and practice of optometry. The manuscript management system is completely online and includes a very quick and fair peer-review system, which is all easy to use. Visit http://www.dovepress.com/ testimonials.php to read real quotes from published authors. 